\title{
RANCANG BANGUN PENDETEKSI FORMALIN DAN RHODAMIN B BERBASIS ARDUINO
}

\author{
${ }^{1}$ Farid Baskoro, ${ }^{2}$ Rizky Susanto \\ ${ }^{1,2}$ Program Studi Teknik Elektro, Fakultas Teknik, Universitas Negeri Surabaya \\ Email: faridbaskoro@unesa.ac.id, rizkysusanto@mhs.unesa.ac.id
}

\begin{abstract}
Abstrak
Formalin dan rhodamin $\mathrm{b}$ merupakan bahan kimia berbahaya yang paling sering disalah gunakan sebagai bahan tambahan pangan sesuai dengan laporan BPOM 2017 yang menunjukkan penyalahgunaan rhodamin mencapai 36\% sedangkan formalin mencapai 32\% padahal hal ini sudah dilarang oleh pemerintah yang telah tertuang dalam SK maupun peraturan kemenkes. Alat ini bermanfaat untuk membantu masyarakat dalam mendeteksi formalin dan rhodamin b, dengan desain yang kecil dan memiliki sumber daya internal alat ini bisa dibawa ke berbagai tempat dengan mudah dan dioperasikan secara langsung tanpa mencari sumber daya PLN. Alat ini memanfaatkan sensor MQ-138 yang berupa sensor gas untuk mendeteksi formalin dan photodiode untuk mendeteksi rhodamin b dengan arduino nano sebagai pusat pengendali dan hasilnya ditampilkan melalui OLED( Organic Light-Emitting Diod). Pada pengujian formalin memiliki nilai error $7 \%-17 \%$ pada bahan tahu, ikan, dan mie basah dengan konsentrasi formalin yang berbeda - beda pada tiap bahan dimana pada bahan tahu memiliki akurasi $86 \%$ - 92\% sementara pada bahan ikan memilki nilai akurasi antara $88 \%$ - 93\% dan pada bahan mie basah memiliki akurasi antara 83\% - 90\%. Pengujian rhodamin b menggunakan 3 larutan dengan konsentrasi yang berbeda - beda dengan hasil pengujian menunjukkan error antara $24 \%-27 \%$ dari ketiga bahan tersebut. Pada alat ini menggunakan 1 buah rechargeable battery dengan kapasitas 3000mAh yang mampu bertahan selama 8 jam

Kata Kunci: Formalin, rhodamin b, arduino, baterai,
\end{abstract}

\begin{abstract}
Formaldehyde and rhodamine $\mathrm{b}$ are hazardous chemicals that are most often misused as food additives according to the 2017 BPOM(Indonesian food and drug administration) report which shows the abuse of rhodamine reaches $36 \%$ while formaldehyde reaches $32 \%$ even though this has been prohibited by the government as stated in the decree and the Ministry of Health regulations. This tool is useful to assist the community in detecting formaldehyde and rhodamine $b$, with a small design and internal resources, this tool can be taken to various places easily and operated directly without looking for electric resources. This tool utilizes the MQ-138 sensor in the form of a gas sensor to detect formaldehyde and a photodiode to detect rhodamine $\mathrm{b}$ with Arduino nano as the control center and the results are displayed on OLED ( Organic Light-Emitting Diode). In the formaldehyde test, it has an error value of $7 \%-17 \%$ for tofu, fish and wet noodles with different concentrations of formaldehyde for each ingredient where the tofu material has an accuracy of $86 \%-92 \%$ while in fish ingredients it has an accuracy value between $88 \%-93 \%$ and the wet noodle material has an accuracy between $83 \%-90 \%$. The rhodamine b test used 3 solutions with different concentrations with the test results showing an error between $24 \%-27 \%$ of the three ingredients. In this tool uses 1 rechargeable battery with a capacity of $3000 \mathrm{mAh}$ which can last for 8 hours.
\end{abstract}

Keywords: formaldehyde, rhodamine b, arduino, battery

\section{PENDAHULUAN}

Melalui program pasar aman dari bahan berbahaya BPOM mengintervensi berbagai pasar untuk mengendalikan peredaran bahan berbahaya serta meningkatkan keamanan, dengan adanya program ini memberikan dampak

Farid : Rancang Bangun Pendeteksi ... menurunnya penggunaan bahan berbahaya yang beredar di pasar, tiap tahun nilai pangan tidak memenuhi syarat semakin turun. Pada tahun 2017 terdapat 537 sampel yang tidak memenuhi syarat dari total 8.950 sampel. Parameter yang diukur dalam syarat pemenuhan syarat melipui 
pengujian formalin, rhodamin b, methyl yellow, dan boraks. Dari 537 sampel tersebut jumlah penyalah gunaan bahan berbahaya yang digunakan ialah $36 \%$ mengandung rhodamin $\mathrm{b}, 32 \%$ mengandung formalin, $32 \%$ mengandung boraks, dan $1 \%$ mengandung methyl yellow. Dari laporan ini diketahui bahwa penyalahgunaan rhodamin $b$ dan formalin menempati urutan pertama dan kedua, padahal penggunaan bahan tersebut sebagai bahan tambahan pangan telah dilarang oleh pemerintah.

Dikarenakan dampak yang bisa ditimbulkan apabila bahan berbahaya tersebut masuk kedalam tubuh Penggunaan formalin dan rhodamin $b$ sebagai bahan tambahan makanan sudah dilarang sejak lama oleh pemerintah Indonesia melaui SK Menkes RI N. 722 tentang Bahan Tambahan Makanan untuk pelarangan formalin dan peraturan menteri kesehatan (permenkes) No. 239/Menkes/Per/V/85 untuk rhodamin b, pelarangan ini dikarenakan dampak negatif yang ditimbulkan apabila masuk kedalam tubuh dalam waktu singkat dapat menyebabkan mual, muntah, rasa perih yang hebat dan dampak sistematis dari konsumsi dalam waktu lama ialah koma, depresi susunan syaraf, dan albuminaria.

Menurut penelitian Reziana Asyfiradayati, dkk dengan judul "Identifikasi Kandungan Formalin Pada Bahan Pangan (Mie Basah, Bandeng Segar Dan Presto, Ikan Asin, Tahu) Di Pasar Gede Kota Surakarta" menunjukkan bahan pangan yang diperdagangkan di wilayah masih terdapat yang mengandung formalin sehingga tidak semua bahan tersebut memenuhi PERMENKES tentang pelarangan formalin sebagai tambahan bahan makanan. Dengan keadaan tersebut Reziana dkk merekomendasikan agar masyarakat perlu segera diberikan informasi tentang keamanan makanan yang dikonsumsi.

Pada penelitian M. Safrul dengan judul "Pendeteksi Kandungan Boraks Dan Formalin Pada Bakso Sapi Berbasis ATMEGA 2560 Menggunakan Jaringan Syaraf Tiruan Backpropagation" menambahkan saran agar selanjutnya alat memiliki dimensi yang kecil berupa box sehingga alat dapat dibawa dan mudah digunakan untuk pengujian di lapangan, serta untuk mempermudah penggunaan di lapagan sebaiknya alat dilengkapi dengan catu daya internal sehingga tidak membutuhkan aliran listrik dari PLN.

Berdasarkan latar belakang tersebut maka dibuatlah penelitian yang berjudul "Rancang Bangun Pendeteksi Formalin dan Rhodamin B Berbasis Arduino". Tujuan dari penelitian ini untuk mempermudah penggunaan alat pendeteksi formalin dan rhodamin $b$ yang bisa dimanfaatkan di lapangan dengan sumber tegangan yang sudah tertanam sehingga tidak memerlukan sumber dari PLN. Penelitian ini juga mampu memberikan informasi formalin pada makanan dan rhodamin b pada minuman.
Alat ini menggunakan sensor gas MQ-138 untuk mendeteksi kandungan formalin yang terdapat pada makanan. Untuk kandungan rhodamin menggunakan photodiode dan LED untuk pemancaran dan pembacaan kandungan rhodamin yang terdapat pada larutan. Sebagai pusat pengolah data dari semua sensor menggunakan arduino nano dengan output yang ditampilkan pada display OLED, pemilihan arduino nano didasarkan atas ukuran yang kecil dan kemampuan yang memadai untuk memproses semua data yang diperlukan.

\section{Formalin}

\section{KAJIAN PUSTAKA}

Formaldehide atau yang biasa disebut metanal merupakan senyawa aldehide yang memiliki rumus kimia $\mathrm{H}_{2} \mathrm{CO}$ yang biasanya berbentuk gas atau cair. Formaldehide terbentuk akibat reaksi oksidasi katalik pada metanol oleh sebab itu formaldehide dapat dihasilkan dari pembakaran bahan yang mengandung karbon dan terkandung pada kebakaran hutan, asap knalpot, dan asap tembakau. Dalam tubuh manusia juga menghasilkan formaldehide dalam jumlah yang sangat kecil sebagai metabolit.

Formalin sendiri ialah larutan formaldehide dalam air. Formalin mengandung $10 \%$ - 40\% formaldehide serta $15 \%$ metanol untuk membatasi polimerisasi, tetapi paling banyak dijumpai formlain mengandung $37 \%$ formaldehide. Karakteristik dari formalin sendiri ialah larutan tidak berwarna dan baunya sangat menusuk.

\section{Rhodamin B}

Rhodamin B adalah zat warna sintetis berbentuk serbuk kristal, berwarna hijau atau ungu kemerahan, tidak berbau, dan dalam larutan berwarna merah terang berfluorensi. Rhodamin B semula digunakan untuk kegiatan histologi dan sekarang berkembang untuk berbagai keperluan seperti sebagai pewarna kertas dan tekstil.

Rumus molekul dari rhodamin $\mathrm{b}$ adalah $\mathrm{C}_{1} \mathrm{NC}_{1}$ serta rumus kimia $\mathrm{C}_{12} \mathrm{H}_{31} \mathrm{CIN}_{2} \mathrm{O}_{3}$ dengan berat molekul sebesar 479.000 rhodamin $\mathrm{b}$ ini sangat mudah larut dalam air menghasilkan larutan merah kebiruan dan berflouresensi kuat jika diencerkan.

\section{Mikrokontroler}

Mikrokontroler merupakan sebuah komputer yang berupa sebuah IC (Integrated Circuit), dimana di dalam mikrokontroler sudah terdapat jalur input output(I/O), memori, mikroprosesor, dan komponen lainnya sehingga mikrokontroler ini mampu mengolah dan memberikan sinyal sesuai program yang terdapat didalamnya. Salah satu dari banyak mikrokontroler merupakan arduino nano yang merupakan produk prosesor yang cukup kecil keluaran arduino, meskipun ukurannya kecil arduino nano sudah 
dilengkapi dengan ATMEGA328, port USB mini-B, 14 buah pin digital I/O yang terdiri dari 6 pin sebagai output PWM dan 8 pin input analog.

\section{MQ-138}

MQ - 138 adalah salah satu sensor gas VOC (volatile organic compound) yang berbahan semikonduktor. Gas VOC sendiri merupakan bahan/senyawa organik yang berupa padat maupun cair dan mudah menguap menghasilkan gas. Bahan - bahan organic ini meliputi bermacam - macam bahan kimia yang mana dapat mempengaruhi kesehatan dalam jangka waktu panjang maupun pendek.

$\mathrm{MQ}$ - 138 sendiri memiliki kemampuan untuk mendeteksi benzena, $\mathrm{NH}_{3}$, alkohol, $\mathrm{CO}$, n-hexana, dll pada umumnya sensor ini digunakan untuk mengukur kualitas udara di bangunan, mendeteksi kandungan terlarut dan detektor pernafasan.

\section{Photodiode}

Photodioda adalah salah satu jenis dioda yang resistansinya berubah - ubah sesuai dengan intensitas cahaya yang jatuh pada diodanya, photodioda terbuat dari bahan semikonduktor. Biasanya yang digunakan adalah silicon ( $\mathrm{Si})$, gallium arsenide (GaAs), indium antimonide (InSb), Indium arsenide (InAs) dan timah sulfide (PBS) bahan - bahan yang digunakan menentukan range panjang gelombang yang mampu di tangkap oleh photodiode misalnya $250 \mathrm{~nm}$ sampai $1100 \mathrm{~nm}$ untuk silicon dan $800 \mathrm{~nm}$ sampai 2,0um untuk GaAs . Dalam mendeteksi rhodamin b memanfaatkan cahaya hijau dikarenakan rhodamin b memiliki nilai serapan tertinggi pada panjang gelombang $523 \mathrm{~nm}$ dan penjang gelombang tersebut berkorelasi dengan serapan cahaya hijau.

\section{METODE PENELITIAN}

\section{Pendekatan}

Instrumen penelitian adalah suatu alat yang digunakan oleh peneliti untuk pengumpulan data. Instrumen pada penelitian ini adalah alat pendeteksi formalin dan rhodamin $\mathrm{b}$ menggunakan software Arduino IDE. Pengumpulan data kuantitatif diperoleh dari hasil pengukuran gas yang dikeluarkan makanan yang mengandung formalin dan rhodamin $\mathrm{b}$ memanfaatkan berkas cahaya hijau yang ditransmisikan oleh LED yg melewati larutan rhodamin yang di tangkap oleh photodiode kemudia didapat informasi kandungan rhodamin.

\section{Persiapan Sampel}

Sampel untuk pengujian formalin merupakan tahu putih, mie basah, dan ikan. Untuk masing - masing sampel akan terdiri dari 4 sample dengan konsentrasi berbeda yang terdiri dari:

a. Sampel tanpa formalin

Sampel merupakan bahan yang tidak dicampurka dengan larutan formalin, untuk memastikan tidak adanya formalin pada bahan dilakukan uji coba menggunaka tes kit formalin.

b. Sampel berformalin $2 \%, 4 \%$, dan $8 \%$

Sampel merupakan bahan yang telah dilakukan perlakuan berupa direndam pada larutan $50 \mathrm{ml}$ yang diberikan formalin sesuai konsentrasi selama 5 menit pada suhu ruangan.

Perhitungan untuk larutan yang digunakan menggunakan persamaan 1 sebagai berikut:

$\mathrm{V}=$

Dimana diketahui:

$\mathrm{V}=\%$ volume zat terlarut

$\mathrm{V} 1=$ volume zat terlarut

$\mathrm{V} 2=$ volume larutan

Untuk larutan $2 \%$

$\mathrm{V}=-$

$\mathrm{V}=2 \%$

Untuk larutan $4 \%$

$\mathrm{V}=-$

$\mathrm{V}=4 \%$

Untuk larutan $8 \%$

$\mathrm{V}=-$

$\mathrm{V}=8 \%$

Persiapan sampel rhodamin b dilakukan dengan cara yang hampir sama dengan persiapan formalin, dengan rumus persen massa per volume, yakni:

$\mathrm{Z}=\ldots \ldots$

Dimana diketahui:

$\mathrm{Z}=$ kadungan rhodamin

$\mathrm{m}=$ massa zat terlarut $(\mathrm{mg})$

$\mathrm{v}=$ volume larutan $(\mathrm{ml})$

untuk larutan 1

$\mathrm{Z}=$

$\mathrm{Z}=0,2 \mathrm{mg} / \mathrm{ml}$

$\mathrm{Z}=200 \mathrm{ug} / \mathrm{ml}$ 
Untuk larutan 2

$\mathrm{Z}=\ldots \ldots$

$\mathrm{Z}=0,1 \mathrm{mg} / \mathrm{ml}$

$\mathrm{Z}=100 \mathrm{ug} / \mathrm{ml}$

Untuk Laarutan 3

$\mathrm{Z}=\ldots \ldots \ldots$

$\mathrm{Z}=0,05 \mathrm{mg} / \mathrm{ml}$

$\mathrm{Z}=50 \mathrm{mg} / \mathrm{ml}$

\section{Rancang Penelitian}

rancangan penelitian berguna untuk menunjukkan tahapan - tahapan yang dilalui selama penyusunan penelitian sampai merumuskan kesimpulan. Gambar 1 rancangan penelitian

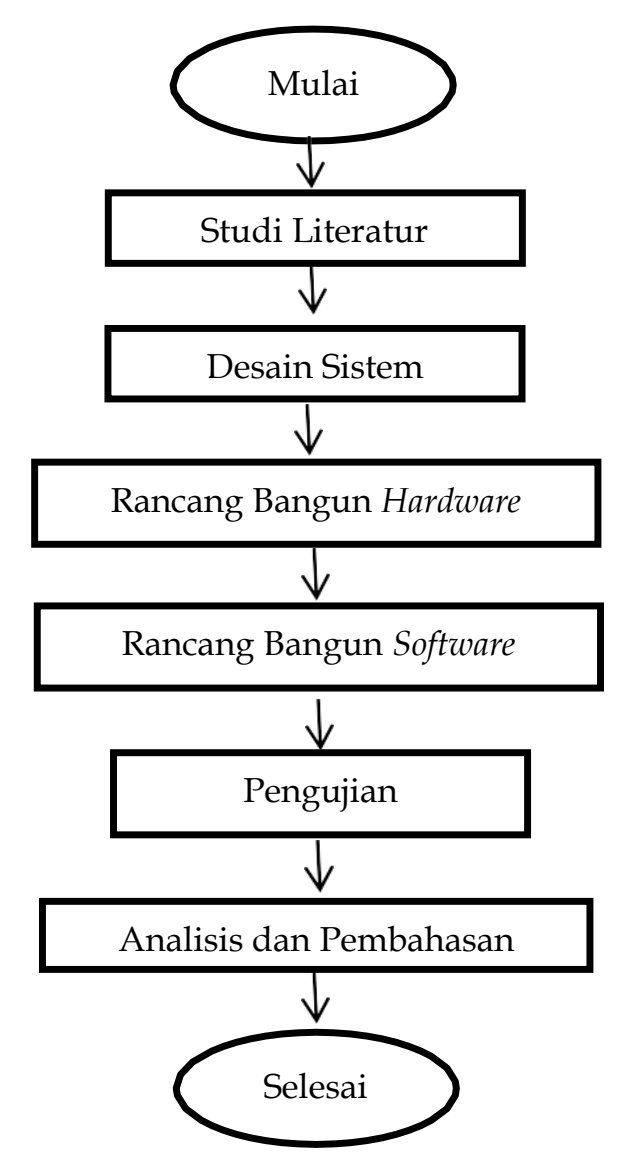

Gambar 1. Rancangan penelitian

\section{Rancang Bangun}

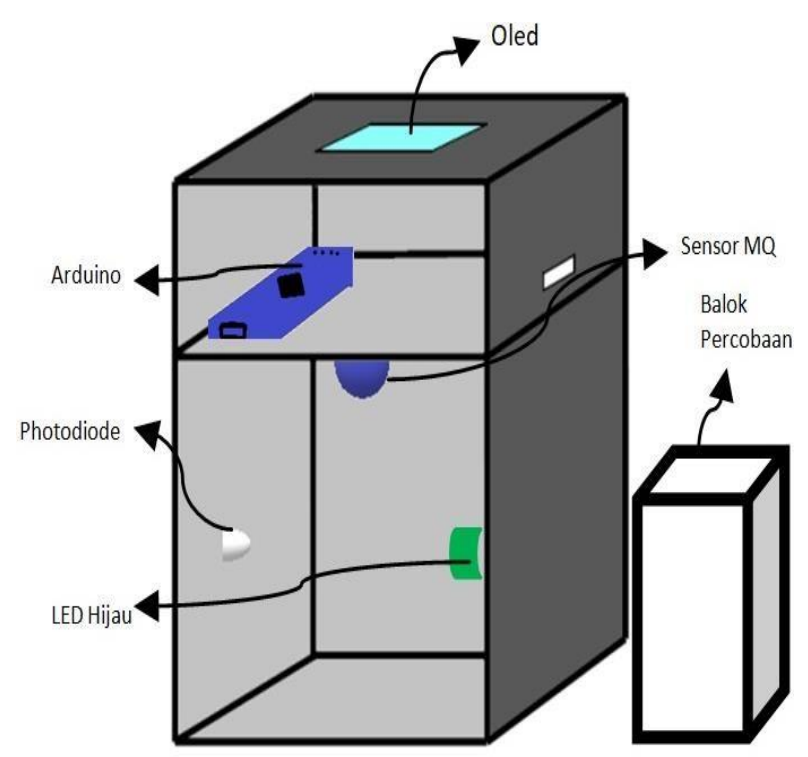

Gambar 2. Rancang Bangun Alat

Rancang bangun pendeteksi formalin dan rhodamin $b$ berupa box balok berbahan akrilik $2 \mathrm{~mm}$ dengan ukuran $14 \mathrm{~cm}$ x 7 $\mathrm{cm} \times 7 \mathrm{~cm}$, yang terbagi menjadi 2 bagian yakni bagian pengujian dan bagian komponen. Bagian pengujian berukuran $11 \mathrm{~cm} \times 7 \mathrm{~cm} \times 7 \mathrm{~cm}$ sementara bagian komponen berukuran $3 \mathrm{~cm} \mathrm{x} 7 \mathrm{~cm} \mathrm{x} 7 \mathrm{~cm}$.

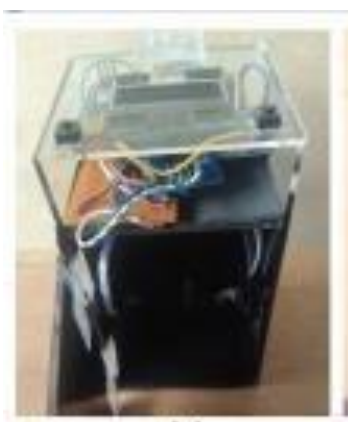

(a)

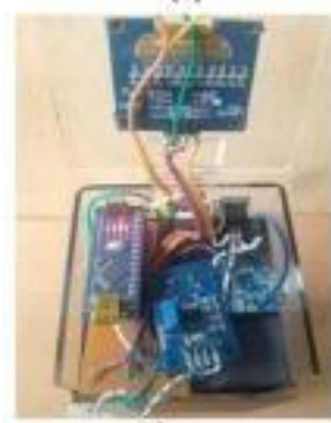

(c)

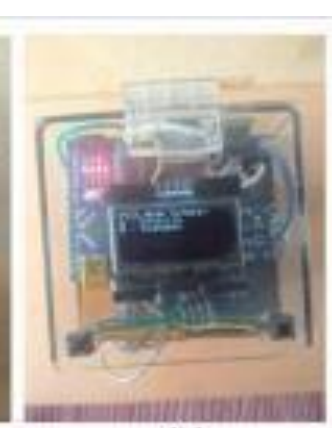

(b)

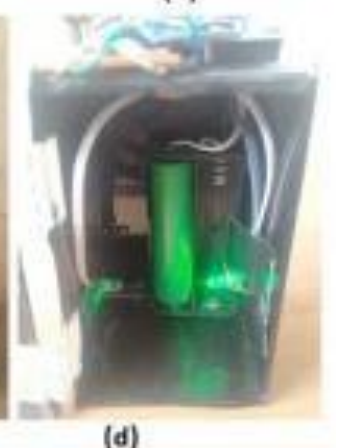

(d)
Gambar 3. Partisi rancang bangun

Keterangan: ( a). Keseluruan alat (b). Alat tampak atas (c). Bagian komponen (d). Bagian pengujian. 
Pada bagian pengujian terdapat photodiode dan LED yang berguna untuk pengujian rhodamin $\mathrm{b}$ serta batteryy holder untuk tempat baterai sebagai sumber tegangan. Pada bagian komponen terdapat komponen utama penyusun rancang bangun ini, yang terdiri dari arduino nano sebagai pusat kontrol dan pemroses data dari sensor. Sensor MQ-138 sebagai sensor pendeteksi formalin melalui gas yang dihasilkan oleh formalin. Modul TP4056 yang berfungsi sebagai charger dan pelindung baterai selama proses pengecasan yang akan melakukan cut-off otomatis apabila tegangan baterai sudah mencapai $4,2 \mathrm{~V}$.

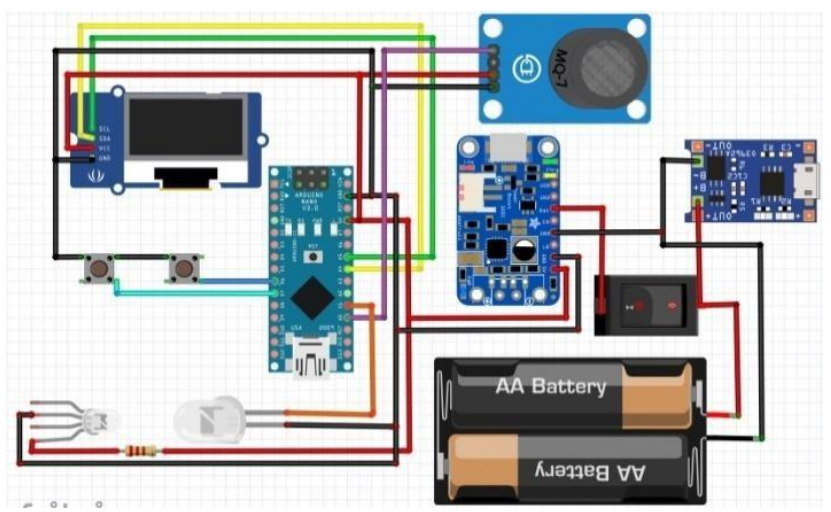

Gambar 4. Wiring keseluruhan komponen

\section{Rancang Software}

Dalam pembuatan program selalu diawali dengan pembuatan kerangka berfikir atau flow chart, dengan adanya kerangka berfikir ini mempermudah programer untuk membuat program ke perangkat keras seperti arduino.

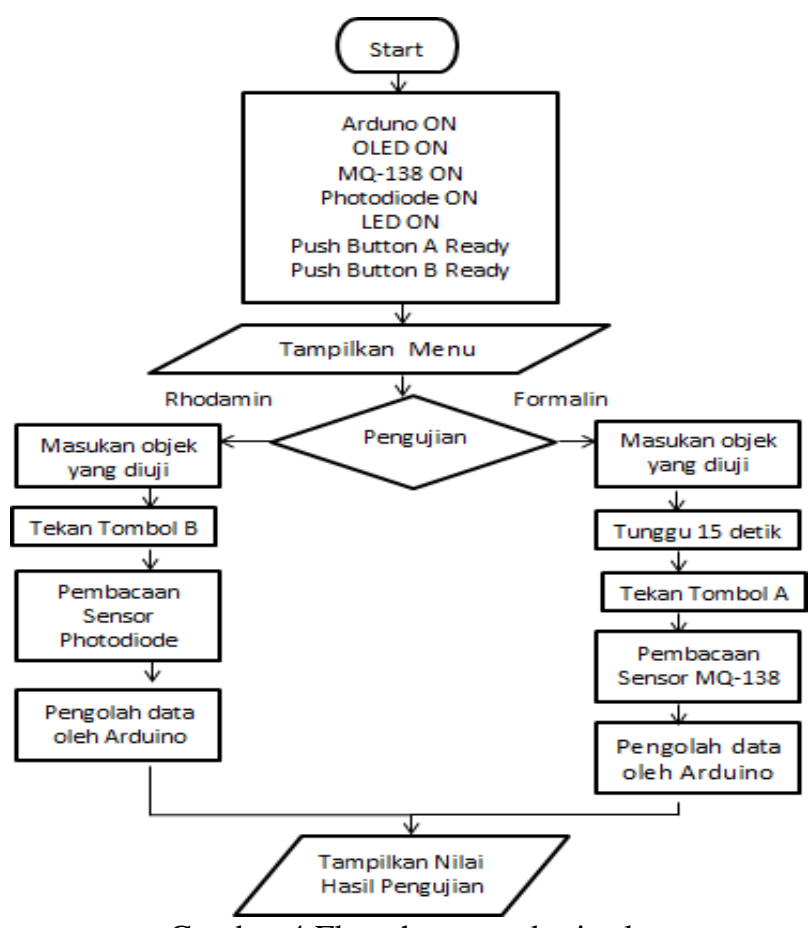

Gambar 4.Flowchart cara kerja alat
Ketika awal menyalakan alat pendeteksi formalin dan rhodamin maka oled akan menampilkan teks " Alat Pendeteksi Formalin dan Rhodamin" dan menu pilihan pengujian. Menu A untuk pengujian formalin dan menu B untuk pengujian rhodamin. Pengujian formalin dilakukan dengan cara memasukkan objek yang diuji berupa makana atau bahan makanan pada tempat pengujian formalin. Kemudian tunggu selama 15 detik lalu tekan push button A dan hasil akan ditampilkan di oled. Untuk pengujian rhodamin dilakukan dengan cara memasukkan larutan kedalam balok uji yang telah disediakan lalu masukkan balok uji kedalam alat dan tekan push button B untuk mengetahui hasil pengujian rhodamin $\mathrm{b}$

\section{HASIL DAN PEMBAHASAN}

Pengujian dilakukan meliputi pengujian baterai, pengujian sensor MQ-138 dan pengujian sensor photodiode.

\section{Pengujian baterai}

Pengujian baterai dilakukan pada baterai 18650 Sony VTC 6 dengan kapasitas 3000mAh 30A tegangan 3,7V dan efisiensi $80 \%$.

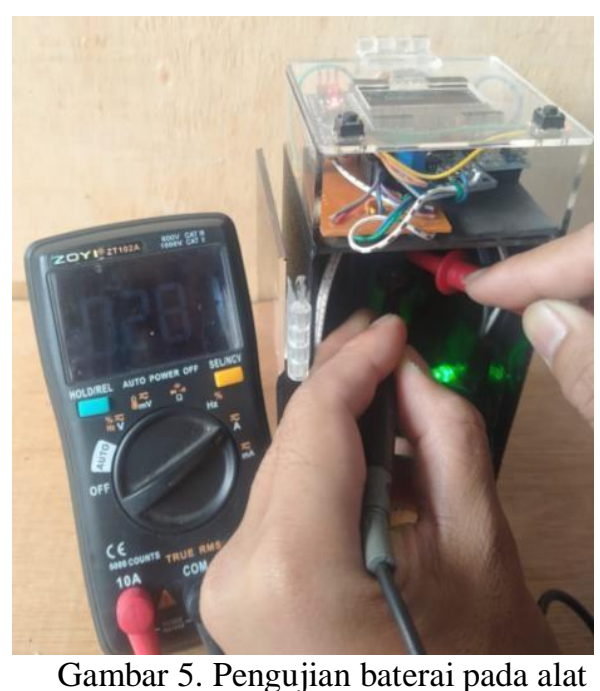

Pengujian menggunakan multimeter digital Zoyi ZT102A untuk mengukur tegangan dan arus dengan hasil pengujian sebagai berikut:

Vbat $=4 \mathrm{~V}$

Valat $=3,8 \mathrm{~V}$

$\mathrm{I} \quad=0,29 \mathrm{~A}$

$\mathrm{P} \quad=$ ValatxI

$=3,8 \times 0,29$

$=1,1$ watt

Keterangan:

Vbat : tegangan awal baterai

Valat : tegangan saat alat dinyalakan 
I : Arus

$\mathrm{P} \quad$ : daya

Dengan hasil perhitungan tersebut maka dapat dihitung lama waktu pemakaian alat.

Arus kerja $\quad$ : I x 1 jam

: $0,29 \times 1$ jam

: $0,29 \mathrm{Ah}$

: $290 \mathrm{mAh}$

Waktu pemakaian $(\mathrm{t})$

$\mathrm{t}=$.

$\mathrm{t}=$

$\mathrm{t}=$

$\mathrm{t}=8,27$ Jam ( 8 jam 16 menit $)$

\section{Pengujian sensor MQ-138}

Pengujian dilakukan dengan cara menaruh sample disekitar sensor yang bertujuan untuk mengetahui jarak efektif sensor, pengujian dilakukan agar mendapat nilai awal dan konstan saat sehingga saat pengujian mendapat nilai error seminimal mungkin.

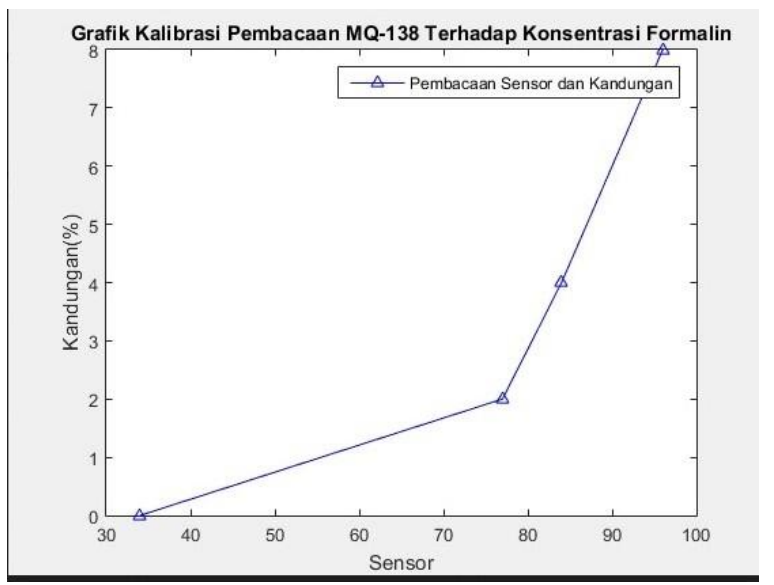

Gambar 6. Persamaan sensor Mq-138

\section{Pengujian photodiode}

Pengujian dilakukan dengan menyusun photodiode dan LED saling berhadapan dengan diantaranya terdapat larutan rhodamin b yang terdapat dalam balok akrilik transparan. Dari hasil pengujian didapat persamaan sebagai berikut

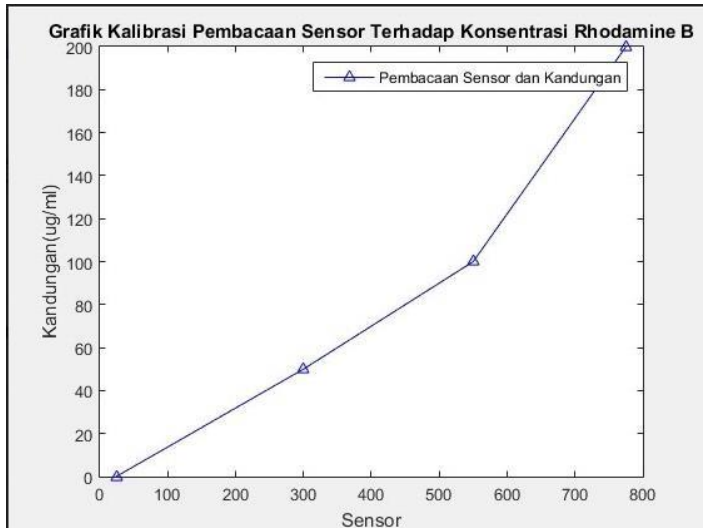

Gambar 7. Persamaan photodiode

Setelah di dapat nilai awal dari setiap pengujian penelitian dilanjutkan dengan pengujian menggunakan sampel yang telah dikondisikan.

\section{Pengujian sampel tahu}

Pada pengujian ini sampel yang digunakan adalah tahu yang sudah memiliki konsentrasi formalin yang berbeda pada masing - masing tahu.

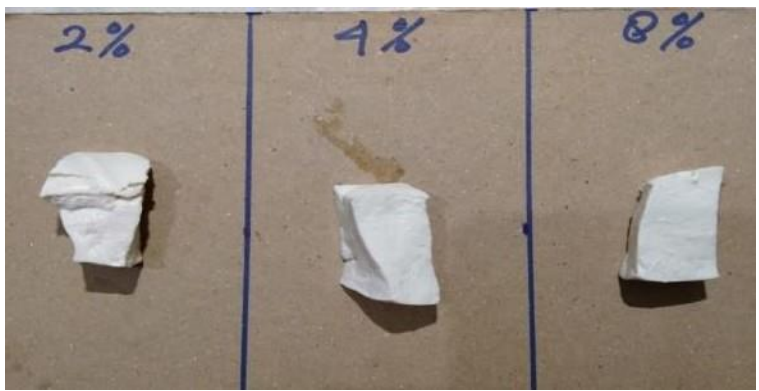

Gambar 8. Sample tahu berformalin

Pada pengujian tahu berformalin di dapat hasil sebagai berikut:

Tabel 1. Hasil pengukuran formalin pada tahu

\begin{tabular}{|c|c|c|c|c|c|c|}
\hline \multicolumn{7}{|c|}{ Tahu } \\
\hline \multirow[b]{2}{*}{ No } & \multicolumn{2}{|c|}{ Konsentrasi 2\% } & \multicolumn{2}{|c|}{ Konsentrasi 4\% } & \multicolumn{2}{|c|}{ Konsentrasi 8\% } \\
\hline & $\begin{array}{c}\text { Hasil } \\
\text { Pengukuran }\end{array}$ & error & $\begin{array}{c}\text { Hasil } \\
\text { Pengukuran }\end{array}$ & error & $\begin{array}{c}\text { Hasil } \\
\text { Pengukuran }\end{array}$ & error \\
\hline 1 & 1,5 & $25 \%$ & 3,48 & $13 \%$ & 7,07 & $12 \%$ \\
\hline 2 & 2,27 & $14 \%$ & 3,48 & $13 \%$ & 7,55 & $6 \%$ \\
\hline 3 & 2,66 & $33 \%$ & 3,89 & $3 \%$ & 7,55 & $6 \%$ \\
\hline 4 & 1,88 & $6 \%$ & 3,89 & $3 \%$ & 7,55 & $6 \%$ \\
\hline 5 & 2,27 & $14 \%$ & 3,89 & $3 \%$ & 7,55 & $6 \%$ \\
\hline 6 & 1,88 & $6 \%$ & 4,32 & $8 \%$ & 7,07 & $12 \%$ \\
\hline 7 & 1,88 & $6 \%$ & 3,48 & $13 \%$ & 8,05 & $1 \%$ \\
\hline
\end{tabular}


Lanjutan Tabel 1. Hasil pengukuran formalin pada tahu

\begin{tabular}{|r|r|r|r|r|r|r|}
\hline 8 & 2,27 & $14 \%$ & 3,48 & $13 \%$ & 7,55 & $6 \%$ \\
\hline 9 & 2,27 & $14 \%$ & 4,32 & $8 \%$ & 7,07 & $12 \%$ \\
\hline 10 & 1,88 & $6 \%$ & 3,89 & $3 \%$ & 6,59 & $18 \%$ \\
\hline 11 & 1,88 & $6 \%$ & 4,32 & $8 \%$ & 7,55 & $6 \%$ \\
\hline 12 & 2,27 & $14 \%$ & 3,89 & $3 \%$ & 7,55 & $6 \%$ \\
\hline 13 & 2,27 & $14 \%$ & 3,48 & $13 \%$ & 7,07 & $12 \%$ \\
\hline 14 & 2,27 & $14 \%$ & 3,48 & $13 \%$ & 8,05 & $1 \%$ \\
\hline 15 & 1,88 & $6 \%$ & 3,89 & $3 \%$ & 7,55 & $6 \%$ \\
\hline \multicolumn{2}{|c|}{$\begin{array}{c}\text { Rata - } \\
\text { rata } \\
\text { error }\end{array}$} & $13 \%$ & & $8 \%$ & & $7 \%$ \\
\hline
\end{tabular}

Dari 15 kali percobaan pada tahu yang mengandung $2 \%$ formalin didapat akurasi rata - rata $87 \%$ dengan akurasi tertinggi $94 \%$ dan terendah $67 \%$, hal ini semakin baik pada percobaan tahu berfomalin $4 \%$ dengan akurasi rata - rata 92\% dengan akurasi tertinggi 97\% dan terendah $87 \%$ sementara pada tahu berformalin $8 \%$ memiliki rata - rata akurasi yang lebih rendah yakni $91 \%$ tetapi memiliki nilai akurasi paling tinggi yang paling bagus yakni sebesar $99 \%$ dengan nilai akurasi paling rendah $82 \%$.

\section{Pengujian sampel ikan}

Sama seperti pengujian pada tahu, pengujian ikan berformalin menggunakan sampel ikan tongkol yang sudah diberikan formalin dengan konsentrasi yang berbeda - beda.

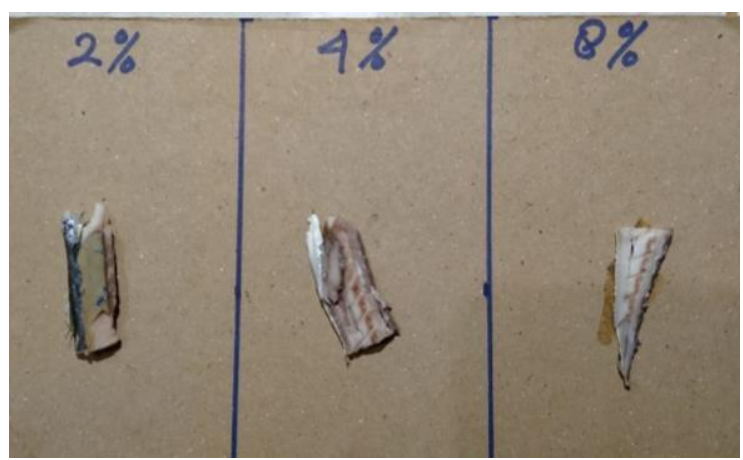

Gambar 9. Sampel ikan berfomalin

Pada pengujian ikan berformalin di dapat hasil sebagai berikut:

Tabel 2. Hasil pengukuran formalin pada ikan

\begin{tabular}{|r|r|r|r|r|r|r|}
\hline \multicolumn{7}{|c|}{$\begin{array}{l}\text { Ik } \\
\text { an }\end{array}$} \\
\hline \multirow{2}{*}{ No } & \multicolumn{2}{|c|}{ Konsentrasi 2\% } & \multicolumn{2}{|l|}{ konsentrasi $4 \%$} & \multicolumn{2}{l|}{ konsentrasi 8\% } \\
\cline { 2 - 7 } & $\begin{array}{l}\text { hasil } \\
\text { pengukura } \\
\text { n }\end{array}$ & error & $\begin{array}{l}\text { hasil } \\
\text { pengukuran }\end{array}$ & error & $\begin{array}{l}\text { hasil } \\
\text { pengukuran }\end{array}$ & error \\
\hline 1 & 1,88 & $6 \%$ & 3,89 & $3 \%$ & 7,07 & $12 \%$ \\
\hline 2 & 2,27 & $14 \%$ & 3,89 & $3 \%$ & 9,06 & $13 \%$
\end{tabular}

Lanjutan Tabel 2. Hasil pengukuran formalin pada ikan

\begin{tabular}{|c|c|c|c|c|c|c|}
\hline 3 & 2,27 & $14 \%$ & 3,48 & $13 \%$ & 8,05 & $1 \%$ \\
\hline 4 & 2,27 & $14 \%$ & 4,32 & $8 \%$ & 7,55 & $6 \%$ \\
\hline 5 & 2,27 & $14 \%$ & 3,89 & $3 \%$ & 8,05 & $3 \%$ \\
\hline 6 & 2,27 & $14 \%$ & 3,89 & $3 \%$ & 7,07 & $12 \%$ \\
\hline 7 & 2,27 & $14 \%$ & 3,48 & $13 \%$ & 7,55 & $6 \%$ \\
\hline 8 & 1,88 & $6 \%$ & 3,89 & $3 \%$ & 8,05 & $1 \%$ \\
\hline 9 & 2,27 & $14 \%$ & 3,46 & $14 \%$ & 8,05 & $1 \%$ \\
\hline 10 & 2,27 & $14 \%$ & 3,89 & $3 \%$ & 7,55 & $6 \%$ \\
\hline 11 & 1,88 & $6 \%$ & 3,89 & $3 \%$ & 7,55 & $6 \%$ \\
\hline 12 & 2,27 & $14 \%$ & 3,46 & $14 \%$ & 8,05 & $1 \%$ \\
\hline 13 & 2,27 & $14 \%$ & 4,32 & $8 \%$ & 7,05 & $12 \%$ \\
\hline 14 & 2,27 & $14 \%$ & 4,32 & $8 \%$ & 7,55 & $6 \%$ \\
\hline 15 & 2,27 & $14 \%$ & 3,89 & $3 \%$ & 7,55 & $6 \%$ \\
\hline \multicolumn{2}{|c|}{$\begin{array}{l}\text { Rata - rata } \\
\text { error }\end{array}$} & $12 \%$ & & $7 \%$ & & $6 \%$ \\
\hline
\end{tabular}

Dari 15 kali percobaan pada ikan dengan berbagai konsentrasi formalin didapat hasil sebagai berikut. Pada ikan dengan konsentrasi formalin $2 \%$ menunjukkan akurasi rata rata sebesar $88 \%$ dengan akurasi tertinffi pada angka $94 \%$ dan terendah pada angka $86 \%$. Yang kedua pada ikan dengan konsentrasi formalin 4\% menunjukkan akurasi ratarata $93 \%$ dengan hasil yang lebih bervariasi dimana akurasi tertinggi mencapai $97 \%$ dan terendah $86 \%$. Sedangkan pada ikan berformalin 8\% mendapat rata - rata akurasi $94 \%$ dengan nilai akurasi tertinggi $99 \%$ dan terendah $82 \%$.

\section{Pengujian sampel mie basah}

Pengujian mie basah tetap menggunakan metode yang sama dengan memberikan formalin dengan konsentrasi berbeda pada masing - masing mie basah.

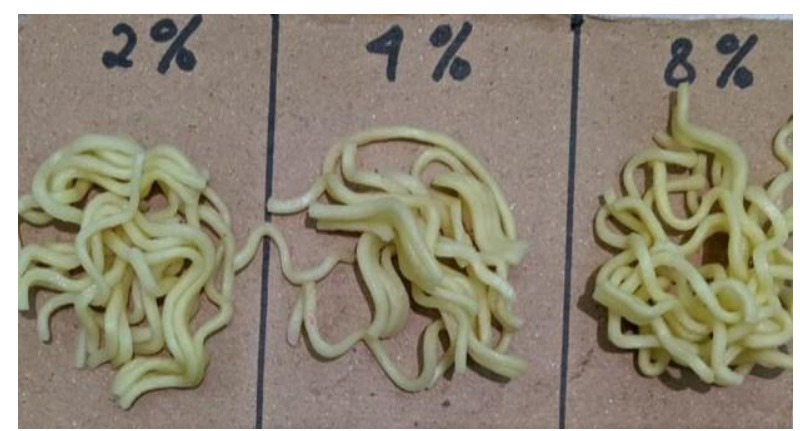

Gambar 11. Sampel mie basah berformalin

Pada pengujian mie basah berformalin didapat hasil yang dapat dilihat pada tabel 3 sebagai berikut: 
JEECOM, Vol. 2, No. 2, Oktober 2020

Tabel 3. Haisl pergukuran formalin pada mie basah

\begin{tabular}{|c|c|c|c|c|c|c|}
\hline \multicolumn{7}{|c|}{$\begin{array}{c}\text { Mie } \\
\text { Basah }\end{array}$} \\
\hline & \multicolumn{2}{|c|}{ konsentrasi $2 \%$} & \multicolumn{2}{|c|}{ Konsentrasi 4\% } & \multicolumn{2}{|c|}{ Konsentrasi 8\% } \\
\hline No & $\begin{array}{c}\text { Hasil } \\
\text { Pengukuran }\end{array}$ & error & $\begin{array}{c}\text { Hasil } \\
\text { Pengukuran }\end{array}$ & error & $\begin{array}{c}\text { Hasil } \\
\text { Pengukuran }\end{array}$ & error \\
\hline 1 & 2,27 & $14 \%$ & 3,89 & $3 \%$ & 8,55 & $7 \%$ \\
\hline 2 & 2,66 & $33 \%$ & 3,89 & $3 \%$ & 9,06 & $13 \%$ \\
\hline 3 & 1,88 & $6 \%$ & 4,76 & $19 \%$ & 8,55 & $7 \%$ \\
\hline 4 & 2,27 & $14 \%$ & 4,32 & $8 \%$ & 7,55 & $6 \%$ \\
\hline 5 & 2,27 & $14 \%$ & 4,76 & $19 \%$ & 6,69 & $16 \%$ \\
\hline 6 & 1,5 & $25 \%$ & 4,76 & $19 \%$ & 8,55 & $7 \%$ \\
\hline 7 & 2,27 & $14 \%$ & 3,73 & $7 \%$ & 6,59 & $18 \%$ \\
\hline 8 & 2,27 & $14 \%$ & 3,89 & $3 \%$ & 7,55 & $6 \%$ \\
\hline 9 & 2,27 & $14 \%$ & 4,32 & $8 \%$ & 8,55 & $7 \%$ \\
\hline 10 & 1,5 & $25 \%$ & 4,76 & $19 \%$ & 7,07 & $12 \%$ \\
\hline 11 & 1,88 & $6 \%$ & 3,73 & $7 \%$ & 7,55 & $6 \%$ \\
\hline 12 & 2,27 & $14 \%$ & 3,89 & $3 \%$ & 8,05 & $1 \%$ \\
\hline 13 & 2,27 & $14 \%$ & 4,32 & $8 \%$ & 8,55 & $7 \%$ \\
\hline 14 & 1,5 & $25 \%$ & 3,89 & $3 \%$ & 9,06 & $13 \%$ \\
\hline 15 & 1,88 & $6 \%$ & 3,73 & $7 \%$ & 8,05 & $1 \%$ \\
\hline \multicolumn{2}{|c|}{ Rata - rata error } & $16 \%$ & & $9 \%$ & & $8 \%$ \\
\hline
\end{tabular}

Pada 15 kali percobaan pengukuran mie basah yang mengandung formalin didapat hasil yang menunjukkan akurasi dan error dari masing - masing konsentrasi dengan penjabaran, pada mie basah berformalin $2 \%$ memiliki akurasi rat - rata sebesar $84 \%$ dengan akurasi terendah $67 \%$ pada nilai pengukuran 2,66 dan akurasi tertinggi sebesar $94 \%$ pada nilai pengukuran 1,88. Pada formalin $4 \%$ memiliki akurasi rata - rata sebesar $91 \%$ dengan rincian nilai akurasi terendah sebesar $81 \%$ dengan nilai pengukuran 4,76 dan akurasi tertinggi sebesar $97 \%$ dengan nilai pengukuran 3,89 . Yang terakhir mie basah dengan konsentrasi formalin $8 \%$ memiliki akurasi rata - rata sebesar $9 \mathrm{w} \%$ dengan akurasi terendah sebesar $84 \%$ pada nilai pengukuran 6,59 dan akurasi tertinggi sebesar $99 \%$ dengan nilai pengukuran 8,05 .

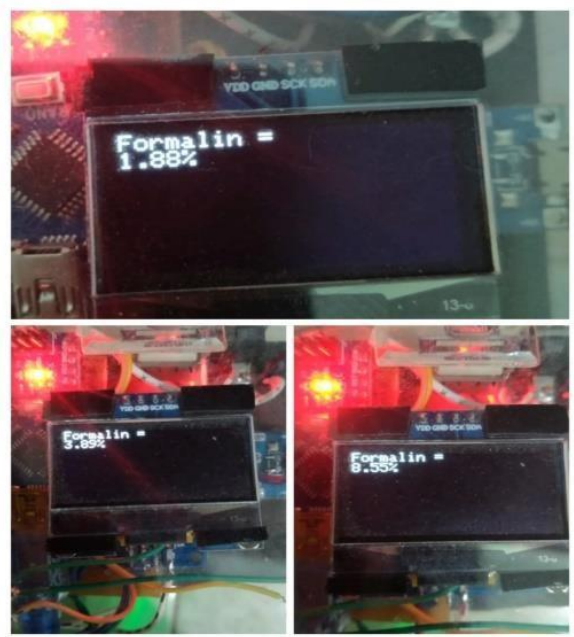

Gambar 12. Tampilan hasil pengujian formalin

\section{Pengujian rhodamin B}

Pada pengujian rhodamin menggunakan larutan air yang telah dicampur dengan kandungan tertentu sehingga menghasilkan kandungan rhodamin yang berbeda - beda untuk masing - masing larutan. Gambar 13 merupakan larutan rhodamin dengan urutan konsentrasi dari kanan yaitu $50 \mathrm{ug} / \mathrm{ml}, 100 \mathrm{ug} / \mathrm{ml}$, dan $200 \mathrm{ug} / \mathrm{ml}$.

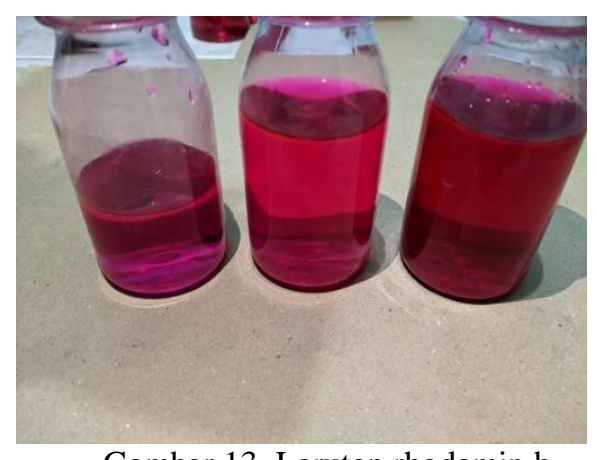

Dengan larutan tersebut dilakukan pengujian yang mendapatkan hasil sebagai berikut:

Tabel 4. Hasil pengukuran rhodamine $b$

\begin{tabular}{|r|r|r|r|r|r|r|}
\hline \multicolumn{7}{|c|}{$\begin{array}{c}\text { Rhodamine } \\
\text { b }\end{array}$} \\
\hline No & $50 \mathrm{ug} / \mathrm{ml}$ & error & $100 \mathrm{ug} / \mathrm{ml}$ & error & $200 \mathrm{ug} / \mathrm{ml}$ & error \\
\hline 1 & 43,08 & $14 \%$ & 133,41 & $33 \%$ & 179,44 & $10 \%$ \\
\hline 2 & 36,54 & $27 \%$ & 135,07 & $35 \%$ & 169,79 & $15 \%$ \\
\hline 3 & 21,83 & $56 \%$ & 134,08 & $34 \%$ & 140,46 & $30 \%$ \\
\hline 4 & 64,69 & $29 \%$ & 137,08 & $37 \%$ & 140,8 & $30 \%$ \\
\hline 5 & 49,07 & $2 \%$ & 135,41 & $35 \%$ & 145,6 & $27 \%$ \\
\hline 6 & 58,69 & $17 \%$ & 129,14 & $29 \%$ & 139,78 & $30 \%$ \\
\hline 7 & 61,45 & $23 \%$ & 122,69 & $23 \%$ & 138,77 & $31 \%$ \\
\hline 8 & 63,53 & $27 \%$ & 86,31 & $14 \%$ & 141,48 & $29 \%$ \\
\hline
\end{tabular}


Lanjutan tabel 4. Hasil pengukuran rhodamine $b$

\begin{tabular}{|r|r|r|r|r|r|r|}
\hline 9 & 68,73 & $37 \%$ & 124,93 & $25 \%$ & 145,6 & $27 \%$ \\
\hline 10 & 53,91 & $8 \%$ & 98,8 & $1 \%$ & 139,78 & $30 \%$ \\
\hline \multicolumn{2}{|r|}{ Rerata error } & $24 \%$ & & $27 \%$ & & $26 \%$ \\
\hline
\end{tabular}

Hasil dari 10x pengukuran rhodamin b menunjukkan nilai rata - rata akurasi tertinggi didapat pada pengukuran rhodamin $50 \mathrm{ug} / \mathrm{ml}$ dengan tingkat akurasi $76 \%$ dan nilai akurasi terendah didapat pada pengukuran $100 \mathrm{ug} / \mathrm{ml}$ dengan tingkat akurasi $73 \%$. Tingkat error alat untuk pengujian rhodamin mencapai $27 \%$.

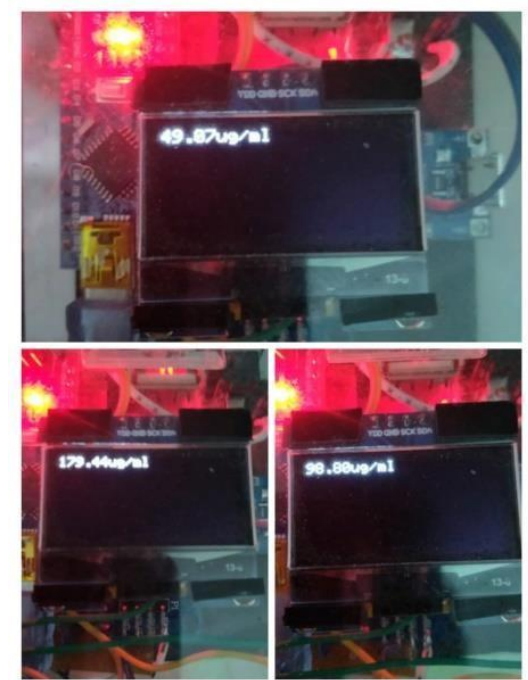

Gambar 14. Tampilan hasil pengujian rhodamin b

\section{Hasil kuesioner tingkat kepuasan pengguna terhadap alat pendeteksi formalin dan rhodamin $b$}

Kuesioner merupakan teknik pengumpulan data yang menggunakan pertanyaan atau pernyataan tertulis guna dijawab oleh responden. Data yang sudah terkumpul nanti akan diubah menjadi bentuk kuantitatif dengan menggunakan metode Skala Likert.

Skala Likert ialah teknik untuk mengukur sikap, pendapat, dan perepsi seseorang atau sekelompok orang tentang fenomena sosial .

Adapun responden rumah tangga merupakan ibu rumah tangga, selaku orang yang paling sering berbelanja di pasar dan familiar dengan bahan - bahan masakan, Responden berjumlah 20 orang.

Berdasarkan hasil pengujian kuesioner yang telah dilakukan maka dapat diketahui:
Tabel 5. Hasil kuesioner tingkat kepuasan pengguna

\begin{tabular}{|r|l|r|}
\hline No & Tujuan & Hasil \\
\hline 1 & Alat mudah dibawa & 4,5 \\
\hline 2 & $\begin{array}{l}\text { Membantu pengguna } \\
\text { untuk }\end{array}$ & 4,3 \\
\hline & $\begin{array}{l}\text { Mendeteksi formalin } \\
\text { untuk } \\
\text { mendeteksi rhodamin b }\end{array}$ & 4,2 \\
\hline 4 & Alat mudah dimengerti & 4,5 \\
\hline 5 & $\begin{array}{l}\text { Mudah untuk charge } \\
\text { baterai }\end{array}$ & 4,3 \\
\hline 6 & Pilihan menu mudah & 4,7 \\
\hline
\end{tabular}

Keterangan: 1. Sangat tidak setuju, 2. Tidak setuju 3. Cukup setuju, 4. Setuju, 5. Sangat setuju

Dari tabel 5 dapat diketahui bahwa responden merasa alat mudah untuk dibawa dalam keperluan sehari - hari serta alat dapat membantu untuk mendeteksi formalin dan rhodamin $b$. Selain itu alat cukup mudah dimengerti dan pilihan menu sangat mudah untuk modul charger perlu sedikit perbaikan.

\section{Kesimpulan}

\section{PENUTUP}

Berdasarkan penelitian yang telah dilakukan, maka dapat disimpulkan bahwa alat pendeteksi formalin dan rhodamin $b$ dapat dioperasikan menggunakan sumber internal sehingga alat lebih mudah untuk di pindahkan dan dioperasikan di lapangan karena tidak membutuhkan sumber daya dari PLN, pada pengujian formalin alat mampu mendeteksi dengan rata - rata error antara 6\% - 16\% yang mana semakin kecil kandungan formalin makan niai error pengukuran cenderung semakin besar. Pengukuran formalin pada mie basah memiliki nilai error yang lebih tinggi dari pada lainnya dikarenakan jumlah mie basah yang dimasukkan ke dalam alat sangat mempengaruhi pembacaan.

Pada pengukuran rhodamin $\mathrm{b}$ alat memiliki nilai error yang cukup tinggi yakni antara $24 \%$ - 27\%. Hal ini dikarenakan tidak adanya tempat yang bisa mengunci balok percobaan sehingga pergeseran penempatan balok menyebabkan perbedaan nilai pengukuran yang cukup besar, selain hal itu pada saat pengujian banykanya laurtan yang dimasukkan kedalam balok percobaan juga menyebabkan perbedaan nilai pembacaan.

Sensor MQ-138 memiliki kemampuan yang baik dalam mendeteksi formalin sehingga bisa dikembangkan, photodiode memiliki beberapa kekurangan dalam mendeteksi kandungan rhodamin $b$

\section{Saran}

Pada penelitian ini ada beberapa hal yang perlu disempurnakan, sampel dan pembanding yang standart 
laboratorium agar pengujian lebih akurat dan sesaui dengan standart. Desain alat yang lebih baik untuk meningkatkan akurasi pembacaan rhodamin $b$, Dan untuk penelitian selanjutnya sebaiknya mencoba menggunakan sensor yang lebih baik dalam mendeteksi rhodamin $b$

\section{DAFTAR PUSTAKA}

[1] Alsuhendra \& Ridawati. (2013). Bahan Toksik dalam Makanan. Jakarta: Rosda

[2] Asyfiradayati, R., Ningtyas, A., Lizansari, M., Purwati, Y., \& Winarsih. (2018). Identifikasi Kandungan Formalin pada Bahan Pangan (Mie Basah, Bandeng Segar dan Presto, Ikan Asin, Tahu) di Pasar Gede Kota Surakarta. Jurnal Kesehatan, 11(2), 12-18. f

[3] BPOM. (2017). Laporan Tahunan Badan Pengawasan Obat dan Makanan tahun 2017. Bpom, 116.

[4] Farmakope Indonesia Edisi III. (1997). Departemen Kesehatan Republik Indonesia.

[5] Gunawan, B., \& Sudarmadji, A.(2013). Pendeteksi Formalin pada Bahan Pangan dengan Sensor Gas. (Budi Gunawan dan Arief Sudarmadji). Laporan Penelitian Pekerti, Kudus, 110 - 115.

[6] Hidayat, S., Mulyani, P. A., Alamsyah, W., Kartawidjaja, M., \& Suryaningsih, S. (2016). Rhodamin B Sebagai Pewarna Berbahaya Pada Makanan Dengan Basis Led Rgb. Spektra: Jurnal Fisika Dan Aplikasinya, 1(2), 123-128.

[7] M. Ssafrul.(2017). Pendeteksi Kandungan Boraks Dan Formalin Pada Bakso Sapi Berbasis ATMEGA 2560 Menggunakan Jaringan Syaraf Tiruan Backpropagation. Thesis. Institut Pertanian Bogor.

[8] Peraturan Menteri Kesehatan RI No. 722/Menkes/Per/IX/1998. (1998). Tentang Bahan Tambahan Pangan.

[9] Sugiyono. (2010). Metode Penelitian Kuantitatif, Kualitatif, dan R\&D. Bandung: Alfabeta

[10] Susanti, I., Rumiasaih., RS, Carlos., Firmansyah, A., (2019). Analisa Penentuan Kapasitas Baterai Dan Pengisiannya Pada Mobil Listrik. Elektra,4(2), 29 - 37.

[11] Utami, W.m Suhendi, A. (2009). Analisis Rhodamin B Dalam Jajanan Pasar Dengan Metode Kromatografi Lapis Tipis. Jurnal Penelitian Sains Dan Teknologi, $10(2), 148-155$.
[12] Widodo, Budiharto. (2005). Panduan Lengkap Belajar Mikrokontroler. Jakarta. PT. Elek Meida Komputindo. 